\title{
Chinese dynasties
}

Zhou:

Spring and Autumn period:

Warring States:

Qin:

Han:

Three Kingdoms:

Six Dynasties:

Northern and Southern Dynasties:

Sui:

Tang:

Five Dynasties:

Northern Song:

Southern Song:

Yuan:

Ming:

Qing:

Republic of China:
1066-221 BC

722-481 BC

c.403-221 BC

221-206 BC

206 BC-AD 220

$220-80$

222-589

317-589

$581-618$

618-907

907-60

960-1127

1127-1279

1279-1368

1368-1644

1644-1911

1911-49 